\title{
SERUM LIPID AND LIPOPROTEINS IN GALLSTONE PATIENTS
}

\author{
Naciye Kurtul', Sadrettin Pençe², Hasan Kocoglu ${ }^{3}$, Hülya Aksoy', Yavuz Capan ${ }^{5}$
}

Kahramanmaraş Sütçü İmam University, Science Faculty, Kahramanmaraş, Turkey: Department of Biochemistry'; Gaziantep University, Medical School, Gaziantep, Turkey: Department of Physiology², Department of Anesthesiology and Reanimation ${ }^{3}$; Atatürk University Medical School, Erzurum, Turkey: Department of Biochemistry ${ }^{4}$, Department of General Surgery ${ }^{5}$

Summary: Serum lipid and lipoprotein concentrations were determined in a group of thirty two gallstone patients and compared to the values obtained in thirty two healthy control subjects. The serum levels of high density lipoprotein cholesterol and lipoprotein(a) in gallstone patients were found to be lower than that of the control group. Total cholesterol, triglyceride, low density lipoprotein cholesterol, apoprotein-A and apoprotein-B concentrations were observed to be higher in gallstone patients than the controls. The differences in triglyceride and low density lipoprotein cholesterol concentration were statistically significant. However, there was no significant difference in high density lipoprotein cholesterol, lipoprotein(a), apoprotein-A, apoprotein-B, and total cholesterol concentrations between groups. It is concluded that gallstone formation may be related to a disturbance in lipid and lipoprotein metabolism.

Key words: Apoprotein; Gallstone disease; Lipoprotein; Lipid

\section{Introduction}

The prevalence of gallstone disease is high in many European countries as well as in the USA (15). Serum lipids and lipoproteins were suggested to be related with the pathogenesis of gallstones (18).

Although there have been numerous studies evaluating the serum lipid status of gallstone patients, these studies yielded inconsistent results. For example, decreased (15) and increased (17) total cholesterol (TC) levels have been reported in gallstone patients. The highest gallstone formation has been reported to be observed at low HDL-C levels and high triglyceride levels (18). Conversely, an unchanged high density lipoprotein cholesterol (HDL-C) and tryglyceride (TG), and reduced serum low density lipoprotein cholesterol (LDL-C) were reported in gallstone patients (17).

The aim of this study was to investigate the possible relationship between serum lipids, lipoproteins and gallstone disease, and compare it with previous studies.

\section{Materials and Methods}

In this study 32 hospitalised gallstone patients undergoing elective cholecystectomy operation ( 27 women, 5 men; 28-65 years; mean: 47.6 years) and 32 healthy donors (control group, 27 women and 5 men; $26-60$ years; mean: 43.4 years) were allocated to the study. Those having diseases other than cholelithiasis were not included to the study in gallstone patients group. In gallstone group patients, there were no cholestasis, and the number of stones were two or more. There were no differences in demographic characteristics of patients between groups, including body mass index, and fasting blood sugar, as morbid obese patients, hypertensive patients and patients with fasting blood sugar of more than $120 \mathrm{~g} / \mathrm{dL}$ were not included to the study.

Blood was obtained in the fasting state and serum samples were analysed for TC, HDL-C, TG, lipoprotein(a) (Lp(a)), apoprotein A (Apo-A), and apoprotein B (Apo-B) concentrations. The serum $\mathrm{TC}$ and $\mathrm{TG}$ concentrations were determined using an enzymatic method (UV test, Boehringer Mannheim) and by using auto-analyser (Hitachi 705). Lp(a), Apo-A, and Apo-B values were determined by nephelometry. LDL-C values were calculated by the Friedewald formula using TC, HDL-C and TG values obtained previously (4).

All the results are presented as mean value \pm standard error (SE). The statistical analyses were performed using the analysis of variance (Anova).

\section{Results}

There was no difference in patient characteristics between groups. Mean $( \pm S E)$ values for fasting serum lipid fractions (TC, HDL-C, LDL-C, TG) and the concentra- 
tions of the Lp(a), Apo-A, and Apo-B in gallstone patients and control group are presented as $\mathrm{mg} / \mathrm{dL}$ in Tables 1 and 2, respectively.

The values for LDL-C, TG, TC, Apo-A, and Apo-B in the gallstone patients were found to be higher than the values obtained in the control group, and these differences were statistically significant $(p<0.05)$. On the other hand, HDL-C, Lp(a) levels were found to be lower in gallstone patients, but this difference was not statistically significant.

Tab 1: Serum lipid concentrations in control and gallstone groups.

\begin{tabular}{|l|c|c|c|c|}
\hline Group & $\begin{array}{c}\text { TC } \\
(\mathrm{mg} / \mathrm{dL})\end{array}$ & $\begin{array}{c}\text { HDL-C } \\
(\mathrm{mg} / \mathrm{dL})\end{array}$ & $\begin{array}{c}\text { LDL-C } \\
(\mathrm{mg} / \mathrm{dL})\end{array}$ & $\begin{array}{c}\text { TG } \\
(\mathrm{mg} / \mathrm{dL})\end{array}$ \\
\hline $\begin{array}{l}\text { Control } \\
\mathrm{n}=32\end{array}$ & & & & \\
Mean \pm SE & $185.60 \pm 19.3$ & $48.40 \pm 7.8$ & $95.35 \pm 13.7$ & $136.40 \pm 23.2$ \\
\hline $\begin{array}{l}\text { Gallstone } \\
\mathrm{n}=32\end{array}$ & & & & \\
Mean \pm SE & $209.23 \pm 11.6$ & $43.35 \pm 3.6$ & $132.70 \pm 8.0$ & $186.91 \pm 9.4$ \\
\hline Significance & $\mathrm{NS}$ & $\mathrm{NS}$ & $\mathrm{P}<0.05$ & $\mathrm{P}<0.05$ \\
\hline
\end{tabular}

TC indicates total cholesterol; LDL, low density lipoprotein; HDL, high density lipoprotein; TG, triglyceride. NS, Not significant.

Tab 2: Serum lipoprotein concentrations in control and gallstone groups.

\begin{tabular}{|l|c|c|c|}
\hline Group & $\begin{array}{c}\mathrm{Lp}(\mathrm{a}) \\
(\mathrm{mg} / \mathrm{dL})\end{array}$ & $\begin{array}{c}\text { Apo-A } \\
(\mathrm{mg} / \mathrm{dL})\end{array}$ & $\begin{array}{c}\text { Apo-B } \\
(\mathrm{mg} / \mathrm{dL})\end{array}$ \\
\hline $\begin{array}{l}\text { Control } \\
\mathrm{n}=32\end{array}$ & & & \\
Mean \pm SE & $46.72 \pm 13.6$ & $151.46 \pm 8.3$ & $91.12 \pm 8.3$ \\
\hline $\begin{array}{l}\text { Gallstone } \\
\mathrm{n}=32\end{array}$ & & & \\
Mean \pm SE & $42.63 \pm 7.2$ & $158.94 \pm 9.4$ & $98.60 \pm 6.2$ \\
\hline Significance & $\mathrm{NS}$ & $\mathrm{NS}$ & $\mathrm{NS}$ \\
\hline
\end{tabular}

Lp(a) indicates lipoprotein(a); Apo-A, apoprotein A; Apo-B, apoprotein B. Ns, Not significant.

\section{Discussion}

It is a widely accepted idea that the gallstone formation is closely related to a disorder in the lipid and lipoprotein metabolism (1). It was reported in a study that the average levels of serum lipids in patients with gallstones were higher than subjects without gallstones (11). However many metabolic factors may affect the gallstone formation (13). In order to standardise the groups in this study hypertensive, atherosclerotic and morbid obese patients were not included to the study. Since other patient characteristics were similar between groups, determinant factors of gallstone formation in these patients seem to be related to the lipid metabolism.
Triglycerides are converted by fatty tissue lipase into free fatty acids and transported in the blood stream to the various organs where, in the presence of glucose, they are resynthesized to triglycerides. In the liver, a large part of the free fatty acids is utilized for the synthesis of the lipids, primarily phospholipids. When the supply of free fatty acids exhausts the metabolic capacity of the liver, as, for example, in fat-rich diets, triglycerides accumulate in the liver cells and may possibly be excreted in the bile. Free fatty acids also stimulate mucin hypersecretion in the gallbladder (12). This mucosal hypersecretion has been assigned a significant role in the formation of gallbladder stones (8).

It is suggested that HDL-C might be a protective factor against gallstone formation in gallbladder (5). HDL-C has been reported to be negatively associated with gallbladder disease or the presence of gallstones (16).Also, Carel found the highest gallstone risk at low HDL-C levels and high TG levels (18). This study confirms results of earlier studies of serum TG $(7,15,18)$ and HDL-C $(5,18)$ levels in gallstone patients.

Contradictory to some studies $(17,15)$ and in accordance with others $(5,7)$, we observed higher concentrations of TC and LDL-C in gallstone patients than did control subjects, although the difference for TC was not statistically significant.

It was reported that serum apolipoproteins might be more sensitive parameters than serum lipids in distinguishing patients with stones from those without stones $(5,19)$. Similar to these findings we have found increased concentrations of serum Apo-A, Apo-B, LDL-C, TC, and TG in gallstone patients.

Data on the association between cholelithiasis and diabetes often are controversial and are mostly based on autopsies or on hospital series. However De Santis et al (2) reported that an altered glucose metabolism may increase the risk of developing cholelithiasis in certain subjects. Gebhard et al (6) reported that obese persons were at risk for cholesterol gallstones because their bile is saturated with cholesterol. Nevertheless, neither diabetic nor obese patients were included in our study to get the accurate results.

In conclusion, the results of this study may indicate that a disturbance in the lipid and lipoprotein metabolism may have a role in gallstone formation.

\section{References}

1. Chen N, Fu L, Xiao L. Changes in serum lipoprotein cholesterol in rabbit model of calcium bilirubinate cholangiolithiasis. Hua Hsi I Ko Ta Hsueh Pao 1994; 25(3):301-4.

2. De Santis A, Attili AF, Ginanni Corradini $S$ et al. Gallstones and diabetes: a casecontrol study in a free-living population sample. Hepatology 1997;25:787-90.

3. Doty JE, Pitt HA, Kuchenbecker HL, Porter-Fink U, Denbesten LW. Role of gallbladder mucus in the pathogenesis of cholesterol gallstones. Am J Surg 1987; 145:54-61

4. Friedewald WT, Levy RI, Frederickson DS. Estimation of the concentration of low density lipoprotein cholesterol in plasma without the use of preparative ultracentrifuge. Clin Chem 1972;18:499-502.

5. Fu X, Gong K, Shao X. The relationship between serum lipids, apolipproteins level and bile lipids. Chung Hua I Hsueh Tsa Chih 1995;708:656-9. 
6. Gebhard RL, Prigge WF, Ansel HJ et al. The role of gallbladder emptying in gallstone formation during diet-induced rapid weight loss. Hepatology 1996;24(3):544-8.

7. Halpern Z, Rubin M, Harach G, Grotto I et al. Bile and plasma lipid composition in non-obese normolipidemic subjects with and without cholesterol gallstones. Liver 1993;13(5):246-52.

8. Harvey PR, Rupar CA, Gallinger S, Petrunka CN, Stassberg SM. Quantitative and qualitative comparison of gallbladder mucus glycoprotein from patients with and without gallstones. Gut 1986;27:374-81.

9. Janowitz P, Wechsler JG, Kuhn K et al. The relationship between serum lipids, nucleation time, and biliary lipids in patients with gallstones. Clin Investig 1992;70:430-6.

10. LaMont JT, Smith BF, Moore JLR. Role of gallbladder mucin in pathophysiology of gallstones. Hepatology 1984;4:51-6.

11. Lin QY, Du JP, Zhang MY et al. Effect of apolipoprotein E gene Hha I restricting fragment length polymorphism on serum lipids in cholecystolithiasis. World J Gastroenterol 1999;5(3):228-30.

12. Migrone G, Greco AV, Finotti EF, Passi S. Free fatty acids: a stimulus for mucin hypersecretion in cholesterol gallstone biles. Biochim Biophys Acta 1988;958:52 9.

13. Pacchioni M, Nicoletti C, Caminiti M et al. Association of obesity and type II diabetes mellitus as a risk factor for gallstones. Dig Dis Sci 2000;45:2000-6.

14. Pemsingh AS, MacPerson BR, Scott GW. Mucus hypersecretion in the gallbladder epithelium of ground squirrels fed a lithogenic diet for the induction of cholesterol gallstones. Hepatology 1987;6:1267-71.
15. Persson GE, Sköld SA, Thulin AJG. Physical constitution and biochemical characteristics of patients with electively diagnosed gallstone disease. Eur J Surg 1991;157:473-6.

16. Scragg RKR, Calvert GD, Oliver JR. Plasma lipids and insulin in gallstone disease: a case control study. Br Med J 1984;289:521-5.

17. Shinchi K, Kono S, Honjo S, Imanishi K, Hirohata T. Serum lipids and gallstone disease. A study of self-defense officials in Japan. Ann Epidemiol 1993;3(6):614-8.

18. Thijs C, Knipschild P, Brombacher P. Serum lipids and gallstones: a case-control study. Gastroenterology 1990;99:843-9.

19. Zhao JC, Xiao LJ, Zhu H, Shu Y, Cheng NS. Changes of lipid metabolism in plasma, liver and bile during cholesterol gallstone formation in rabbit model. World J Gastroenterol 1998;4(4):337-9.

Submitted October 2001.

Accepted April 2002.

Sadrettin Pence MD, PhD, MBA, Gaziantep University, Medical Faculty, Department of Physiology, Gaziantep, Turkey. E-mail: sadrettinpence@hotmail.com 